\title{
Vector-borne diseases, climate change and healthy urban living: Next steps
}

\author{
Mathieu $\mathrm{K}^{1}$, Karmali $\mathrm{M}^{1 *}$ \\ Affiliation \\ 1 Institute for Health and Social Policy, McGill University, Montréal, QC \\ *Correspondence: mkarmali@rogers.com
}

Suggested citation: Mathieu K, Karmali M. Vector-borne diseases, climate change and healthy urban living: Next steps. Can Comm Dis Rep 2016;42:219-21. https://doi.org/10.14745/ccdr.v42i10a13

\section{Introduction}

The abstracts in this issue reflect key presentations given at a workshop in Montréal in April 2016 (1) to discuss vector-borne diseases (VBDs) in Canadian cities from an interdisciplinary perspective, in the context of climate change and healthy urban living (2-11). A key issue examined was: How are climate change and healthy urban living linked together and what do they mean for the future of VBDs in Canadian cities? The following summary seeks to highlight the key points of the workshop, their interconnectivity and the needs, gaps and opportunities that emerged from the presentations and discussions.

\section{The global context}

VBDs, such as dengue fever, chikungunya and Zika virus infection typically transmitted by certain species of aedes mosquito, are emerging or expanding infectious disease threats globally, especially in low- and middle-income countries. The factors that can cause them to emerge include rapid uncontrolled urbanization and population growth, overcrowding, lack of adequate housing and sanitation infrastructure, climate change, pathogen evolution and deteriorating vector control (1-4). In endemic areas of Africa and Asia, dengue, chikungunya and Zika viruses were typically maintained by wildlife reservoir hosts and several mosquito species. Spillover to human populations occurred when people became infected from contact with wilderness mosquitoes. Today, these diseases are almost entirely maintained in human-to-human transmission cycles. Consequently, mosquito-borne diseases are spread to new regions of the world where competent vectors exist, without animals taking part in transmission cycles, increasing the risk of global outbreak. This trend is further exacerbated by climate warming, which can promote vector replication and disease transmission in previously nonendemic regions (3). In addition, the emergence and expansion of VBDs in resource-limited countries with weak surveillance capacity and health systems heightens the risk of global spread (3). Together, these new trends emphasize the need for coordination and partnerships to address emerging challenges of VBDs globally and in Canada (3).

\section{VBDs in Canada}

Historically, VBDs of concern to public health were rare in Canada but in recent years, the mosquito-borne West Nile virus infection and the tick-borne Lyme disease have emerged as significant public health threats $(4,5)$. West Nile virus infection is the most common mosquito-borne illness in Canada. This virus is maintained in nature by cycling between culex mosquitoes and certain bird species. Lyme disease, caused by the bacterium Borrelia burgdorferi, is the most common tick-borne disease in Canada. This infected tick is maintained in small mammals such as mice. Currently, vectors for both diseases have adapted to urban areas and live, feed and reproduce in close proximity to humans. West Nile virus is now endemic in Canada although its incidence fluctuates from year to year. The incidence of Lyme disease is steadily increasing as the geographic area covered by the ticks expands (4-6).

Canada has surveillance programs that track Lyme disease and West Nile virus infection effectively (5). Of concern remains the risk that "exotic" VBDs such as chikungunya and Zika could advance northwards from our southern neighbors as a result of increasing global temperatures that promote replication of aedes mosquitoes and virus transmission $(4,5)$.

\section{Impact of the urban environment and climate change on VBDs}

Growing evidence points to the built urban environment, including urban sprawl, as a risk factor for chronic diseases such as obesity, diabetes and respiratory problems. In part, these diseases result from a dependence on cars for transportation and reduced opportunities for physical activity (6-8). Reducing urban sprawl and making cities more connected and walkable with parks and green and blue spaces can contribute to healthier living (6-8).

Urban sprawl also has a number of ecological effects because of its effect on land cover and local microclimate, water, flora and fauna and habitat availability for vector and host species and vector capacity. The growth, survival and behaviour of mosquitoes and ticks are highly sensitive to environmental temperatures which, in turn are influenced by urban heat island effects. This means temperatures in urban areas are higher 
than in the surrounding rural areas (6). Efforts to mitigate heat island effects by creating more green and blue places such as parks and lakes could promote replication of mosquitoes, especially if combined with climate warming (8). This may also be exacerbated by pools of stagnant water associated with particular types of landscape and drainage design in both urban and suburban areas $(3,4,6,8)$.

\section{Mitigation and adaptation}

Increasing global temperatures are a major risk factor for the expansion of emerging VBDs to countries with temperate climates. Although mitigation of climate change has become a global priority, this remains an ongoing challenge with limited prospects for improvement in the short to medium term. Strategies include addressing social determinants of health (especially in low- and middle-income countries), reducing heat island effects and urban sprawl, and promoting urban design principles that enhance healthy living while minimizing opportunities for vector breeding.

Increased surveillance of currently endemic VBD such as Lyme disease and West Nile virus (9), close monitoring including both human surveillance and vector surveillance (9), of possible oncoming VBDs in areas at risk for emergence and rapid case-detection for travel-related arrival of exotic VBDs needs to be prioritized $(4,5)$. A strong communication strategy should be developed for the public on risk reduction, and for physicians on diagnosis and treatment (9).Messaging about personal protection measures also needs to be adapted to take into account changing urban populations and urban millennials' response to risks and threats (10).

Lastly, there is an urgent need to evaluate and further develop vector control methods. For example, pyrethriod insecticides, larvicides and other chemicals are in use, but data on their effectiveness and safety are limited (11).

\section{Needs, gaps and opportunities}

There is general consensus on the need to continue to advocate strongly against climate change to reduce the risk of VBDs. This could include:

- Enhancing interdisciplinary and multi-sectoral collaboration (8);

- $\quad$ Overcoming the silo mentality that tends to develop within and across sectors of policy and practice (8);

- Informing those involved with public health and policy and urban affairs of new knowledge and recommendations; and

- $\quad$ Expanding research to:

- Develop prediction models using tools such as geographic information system (GIS) to improve assessment of the risks of VBD emergence associated with migration, international travel and settlement patterns $(2,4)$;

- Study the risks and benefits of insecticides including pyrethroids and larvicides (11);

- Gather more data on the behaviours of specific population groups especially with regard to risk-taking, international travel and changing habits and interests, which increase transmission risks of VBDs (10);

- Study the drivers of VBD emergence and transmission to devise better intervention programs (3);

- Study the interplay of climatic and social determinants in order to better understand their intricate relationship with potential emergence of VBDs in cities (2); and

- Analyze the costs and economic impacts of interventions versus no action.

Gaps at the local level could be filled by:

- Understanding the behavioural trends driving urban sprawl and population dynamics in and around urban centres to help develop effective policies at all levels (6);

- Understanding the particular types of landscape design (e.g. isolated patches vs. connected natural areas) that can increase or reduce the reproduction, survival and feeding of vectors, especially in built environments, and optimize urban planning and land-use strategies in urban and periurban areas to minimize the risks of VBDs (6);

- Intervening at the local level to address climate change because its effects are felt at the local level; and

- Improving the regulatory regime to control urban sprawl $(6,8)$.

Strategies at the global level include:

- Implementing the United Nations Strategic Development Goals to address the problem of VBDs and other emerging infectious diseases (1); and

- Continuing action against climate change.

In terms of next steps, a structured symposium was proposed for which invitees would prepare detailed position papers and an agenda for in-depth research would be articulated, that could lead to focused applications for collaborative interdisciplinary research (8).

\section{Conclusion}

Both in a global context and in Canada, VBDs are of highest concern when placed in the context of climate warming and changes in land-use patterns. The built environment of cities is an important determinant of health. Enlightened urban design can help lower rates of chronic disease and limit the impacts of VBDs. This workshop, with participants from different disciplines and sectors, succeeded in promoting an appreciation of the many different perspectives that should be taken into account in order to look at the future in a climate-change context and to coordinate efforts for a global health partnership.

\section{Conflict of interest}

None.

\section{References}

1. Alabaster G. Global policy challenges for urban vectorborne disease risks. Can Comm Dis Rep 2016;42:203-4. 
http://www.phac-aspc.gc.ca/publicat/ccdr-rmtc/16vol42/drrm42-10/ar-05-eng.php.

2. Berrang-Ford L, Harper SL, Echhardt R. Vector-borne diseases: Reconciling the debate between climatic and social determinants. Can Comm Dis Rep 2016;42:211-2. http://www.phac-aspc.gc.ca/publicat/ccdr-rmtc/16vol42/drrm42-10/ar-09-eng.php.

3. Kulkarni MA. Global spread and impacts of emerging vector-borne diseases. Can Comm Dis Rep 2016;42:198-9. http://www.phac-aspc.gc.ca/publicat/ccdr-rmtc/16vol42/drrm42-10/ar-02-eng.php.

4. Ogden $\mathrm{NH}$. Vector-borne disease, climate change and urban design. Can Comm Dis Rep 2016;42:202. http://www.phacaspc.gc.ca/publicat/ccdr-rmtc/16vol42/dr-rm42-10/ar-04eng.php.

5. Lindsay LR. Present state of common vector-borne diseases in Canada. Can Comm Dis Rep 2016;42:200-1. http://www. phac-aspc.gc.ca/publicat/ccdr-rmtc/16vol42/dr-rm42-10/ar03-eng.php.

6. Jaeger JAG, Nazarnia N. Social and ecological impacts of the exponential increase of urban sprawl in Montréal. Can
Comm Dis Rep 2016;42: 207-8. http://www.phac-aspc.gc.ca/ publicat/ccdr-rmtc/16vol42/dr-rm42-10/ar-07-eng.php.

7. Booth GL. Built environment and health. Can Comm Dis Rep 2016;42:205-6. http://www.phac-aspc.gc.ca/publicat/ccdrrmtc/16vol42/dr-rm42-10/ar-06-eng.php.

8. Luka N. Emerging challenges of vector-borne diseases for Canadian cities. Can Comm Dis Rep 2016;42:217-8. http:// www.phac-aspc.gc.ca/publicat/ccdr-rmtc/16vol42/drrm42-10/ar-12-eng.php.

9. Lowe AM. Public health intervention strategies to tackle vector-borne diseases in Quebec. Can Comm Dis Rep 2016;42:213-4. http://www.phac-aspc.gc.ca/publicat/ccdrrmtc/16vol42/dr-rm42-10/ar-10-eng.php.

10. Boudreau JA. Understanding how people react to risk. Can Comm Dis Rep 2016;42:209-10. http://www.phac-aspc. gc.ca/publicat/ccdr-rmtc/16vol42/dr-rm42-10/ar-08-eng.php.

11. Chevrier J. Balancing the risks and benefits of insecticide use for vector control: The Venda Health Examination of Mother, Babies and their Environment (VHEMBE) Study. Can Comm Dis Rep 2016;42:215-6. http://www.phac-aspc.gc.ca/ publicat/ccdr-rmtc/16vol42/dr-rm42-10/ar-11-eng.php.

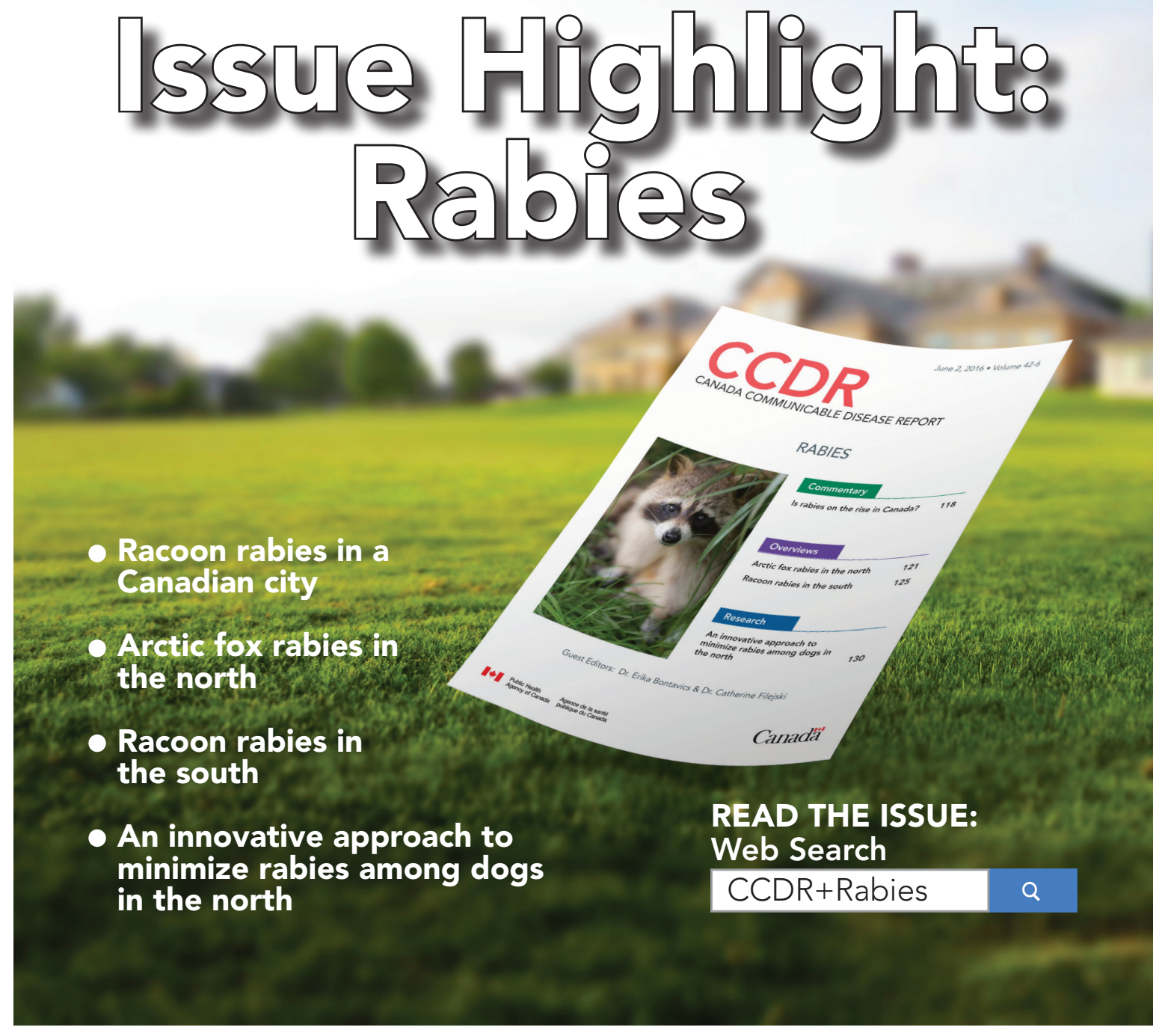

Page 221 CCDR • October 6, 2016・Volume 42-10 